DOI 10.37882/2223-2982.2021.03-2.28

\title{
НАУЧНО-ПОПУЛЯРНЫЙ ПЕДАГОГИЧЕСКИЙ ДИСКУРС: СИСТЕМООБРАЗУЮЩИЕ ХАРАКТЕРИСТИКИ И ПРИЗНАКИ (НА МАТЕРИАЛЕ АНГЛИЙСКОГО ЯЗЫКА) ${ }^{1}$
}

\section{POPULAR SCIENCE PEDAGOGICAL DISCOURSE: SYSTEM'S FEATURES AND PECULIARITIES (ON THE ENGLISH LANGUAGE MATERIAL) ${ }^{2}$}

\section{G. Nersesyan}

Summary: The article represents the analysis of the English popular science pedagogical discourse which is considered an institutional language space. With the help of the linguopragmatic and discourse approaches, the author deduces participants, chronotope, genre, purpose, functions, axiologically charged concepts as the main components of the popular science pedagogical discourse. The relevance of the paper is due to both the role of the pedagogical communication in modern society and growing significance of the popular science pedagogical texts in the processes of people's socialisation and professional development.

Keywords: institutional discourse, popular science pedagogical discourse, pedagogical discourse, discourse participants, value concept.

\author{
Нерсесян Гаянэ Робертовна \\ Аспирант, ФГБОУ ВО «Пятигорский государственный \\ университет» \\ nersesyangr@gmail.com
}

Аннотация: Данная статья представляет собой исследование англоязычного научно-популярного педагогического дискурса. В процессе анализа автор подходит к данному типу дискурса как к институциональному лингвопространству. С помощью лингвопрагматического анализа и дискурс-анализа автор выводит компоненты научно-популярного педагогического дискурса, а именно участников общения, хронотоп, жанр, цель, функции, аксиологически детерминированные концепты. Актуальность исследования обусловлена ролью педагогической коммуникации в современном обществе и увеличивающейся значимостью научно-популярных педагогических текстов в процессе социализации и профессионализации личности.

Ключевые слова: институциональный дискурс, научно-популярный педагогический дискурс, педагогический дискурс, участники дискурса, ценностный концепт.
K ак отмечают современные ученые, нынешняя система образования и, следовательно, педагогическая наука служит развивающемуся постиндустриальному обществу [12], основной деятельностью которого становится потребление и производство информации или, другими словами, процесс коммуникации. В этой связи актуальным становится исследование научнопопулярного педагогического дискурса [далее - НППД] как разновидности педагогической коммуникации, позволяющей судить о возникающих в настоящее время образовательных проблемах общества, отслеживать передовые достижения и тенденции систем обучения и воспитания, а также определять преобладающие в их пространстве ценностные установки.

Несмотря на достаточно большое количество научных работ, посвященных педагогической коммуникации, в лингвистике до сих пор отсутствуют исследования научно-популярного педагогического дискурса, которые позволили бы определить ключевые компоненты рече- мыслительной деятельности человека, интегрирующего образовательные и педагогические идеи и представления внутри и за пределами педагогического сообщества. Целью данного исследования является выявление дискурсивных черт и специфики научно-популярного педагогического дискурса, как ранее не изучаемого вербального пространства. С целью выполнения данной задачи автор прибегает к методу сбора фактического материала, анализ которого обеспечивает достоверность получаемых результатов; дискурс-анализу, с целью выведения основополагающих компонентов научно-популярного педагогического дискурса, а также способов их репрезентации в речевом пространстве; лингвопрагматическому анализу, который помог бы определить функциональную нагруженность научно-популярных педагогических текстов.

В результате сбора фактического материала были отобраны пятьдесят текстовых фрагментов, посвященных образовательным процессам в целом и педагогиче-

Исследование выполнено при финансовой поддержке РФФИ в рамках научного проекта № 20-012-00364 А (руководитель - Багиян А.Ю.).

2 The reported study was funded by RFBR according to the research project № 20-012-00364 A (project executive - Alexander Y. Bagiyan). 
ским практикам в частности. Данные статьи представлены в англоязычных печатных и электронных изданиях, полностью или частично освещающих процессы преподавания иностранных языков (Language magazine: Improving Literacy \& Communication, Babel: the language magazine, Unravel, TOPICS, EFL Magazine - The magazine for English language teachers).

Итак, в процессе анализа научных трудов становится очевидным активное развитие исследований дискурса с позиции коммуникативного подхода. Это подтверждается работами по анализу репрезентаций в языке этнических и культурных особенностей определенного народа $[6,13]$, исследованиями характеристик коммуникантов, целей, стратегий, контекста их общения $[3,5,7,11]$, т.е. тексты анализируются с учетом сопровождающих ее экстралингвистических факторов, в том числе институциональных.

Институциональная коммуникация исследуется наукой как общение людей, принадлежащих определенной социальной или профессиональной группе [3]. Среди типов институционального дискурса исследователи выделяют педагогический [Там же], как профессиональное речевое событие, для которого присущи собственные коммуникативные черты.

Так как общее представление о педагогическом институте складывается по совокупности устной и письменной коммуникации, разворачивающейся вокруг педагогических процессов, педагогический дискурс вынужден удерживать баланс между доступностью изложения и научным повествованием, в особенности если речь идет о популяризации научных достижений и идей, формировании достоверного информационного пространства и вовлеченности в него читателя, поддержании интереса общества к жизни научного, в данном случае педагогического, сообщества [2, стр. 43]. Данные задачи берет на себя научно-популярный педагогический дискурс, который определяется нами как совокупность научно-популярных текстов, отражающих передовые идеи и исследования педагогического сообщества и анализирующих актуальные педагогические процессы и технологии в глобальном образовательном контексте. В результате исследования мы также можем охарактеризовать НППД как институциональный, т.е. репрезентирующий собственные системообразующие черты. Для большей ясности обратимся к текстовому фрагменту НППД.

1. "Storytellers have several ways of making input comprehensible; these methods have been called "elaborative assistance" (McQuillan, 1993) and "comprehension-aiding supplementation" (Krashen, Mason, and Smith, 2018). <...> They include providing background information (telling listeners something about the story in advance, telling stories that have familiar settings or characters) and providing visual information (pictures and drawings) and linguistic information (synonyms, descriptions, translation for second language acquirers)" [Language magazine: Improving Literacy \& Communication, https://www. languagemagazine.com/].

Итак, формат построения данного текста, освещаемые в нем профессиональные знания и используемые языковые средства говорят об авторском присутствии, а точнее об авторе-специалисте, владеющем профессиональной картиной мира, в которой хранится информация о педагогических методах обучения чтению (elaborative assistance, comprehension-aiding supplementation), их разработчиках (McQuillan, 1993; Krashen, Mason, and Smith, 2018) и содержании (background information, visual information, linguistic information). Использование автором статьи конкретных названий педагогических методов и средств обучения значит то, что реципиентами данного сообщения являются читатели-профессионалы, являющиеся полноценными представителями педагогического сообщества, для которых авторский выбор узкоспециализированных слов не является проблемой. Однако для реципиентов незнакомых с представленными педагогическими явлениями, понимание выбранной лексики может представлять определенные сложности. Это подтверждается тем, что автор прибегает к расширению информации с помощью лексических единиц telling listeners something about the story in advance, telling stories that have familiar settings or characters, pictures and drawings, synonyms, descriptions, translation for second language acquirers. Доступные для большего количества людей слова облегчают процесс донесения информации для разного типа реципиентов. Логично предположить, что таким образом автор соблюдает фактор адресованности или развернутости на слушателей [1], которые в научнопопулярном педагогическом дискурсе включают в себя непрофессионалов или начинающих специалистов. Таким образом, можно прийти к выводу о том, что 1) для НППД характерно наличие определенных участников общения, которые могут быть представлены в виде диад «специалист <-> специалист» и «специалист <-> неспециалист». Отметим, что под «неспециалистом» мы понимаем как неподготовленного, так и подготовленного (молодой специалист) реципиента; 2) наличие диад «специалист <-> неспециалист» в НППД обусловливает упрощенное вербальное поведение адресантов.

Помимо наличия участников общения данный пример также можно охарактеризовать пространственновременной соотнесенностью описываемых событий, иначе говоря, выделить в качестве присущих ему черт хронотоn текста [10]. Посредством реализации своих функций хронотоп текста в НППД выстраивает виртуальную реальность, которая помогает читателю ориентироваться в действительности. Так, в приведённом 
выше примере с помощью хронотопа автор интегрирует читателя в педагогическое пространство посредством использования видо-временных форм глаголов, обозначая определенные средства обучения чтению как используемые сегодня (Storytellers have several ways of making input comprehensible), методы обучения чтению, которые были разработаны относительно недавно (these methods have been called), что, в свою очередь, может говорить об их актуальности. Кроме этого, в примере представлены имена авторов и годы (McQuillan, 1993; Krashen, Mason, and Smith, 2018) разработки методик; данная информация разворачивает тему обучения чтению, что способствует большей степени интеграции читателей в обучающую среду и получению ими бо́льших педагогических знаний. Заметим, что в пределах приведенного текстового фрагмента, хронотоп также выполняет регулятивную функцию. Использованная автором темпоральная лексема in advance и герундий providing (They include providing background information $<\ldots$ in advance) сообщают читателю, что определенная информация должна быть предоставлена обучающимся до того, как они приступят непосредственно к чтению текста. Таким образом, автор иллюстрирует грамотный подход к процессу обучения чтению, что, в свою очередь, регулирует действия участников общения.

Отметим, что хронотоп дискурса [10], т.е. сам факт того, что данная дискуссия, посвященная процессу обучения чтению, происходит в настоящее время (данный исторический период) и в пределах англоязычного научно-популярного дискурса, обусловливает цели, жанры, функции и ценности современного англоязычного НППД.

Одним из жанров НППД, к которому относится приведенный текстовый фрагмент, является информационноописательная статья, которая в данном случае описывает процесс обучения чтению и информирует читателей о том, какие шаги стоит предпринять (providing background information $\langle\ldots>$ and providing visual information <...> and linguistic information), чтобы обеспечить успешное усвоение материала обучающимися (making input comprehensible). В рамках анализируемых научнопопулярных педагогических текстов информационноописательная статья предполагает знакомство читателей с профессиональной точной зрения о построении обучающего процесса, совершенствование знаний для личностного и профессионального становления неспециалистов и саморазвития специалистов, а также популяризацию актуальных педагогических знаний. С нашей точки зрения, выражение данных смыслов в пределах НППД служит ключевой цели не только англоязычного, но всего мирового педагогического сообщества, а именно реализации профессиональной педагогической деятельности, желанию педагогов определять и направлять свое существование, подчинять его достижению обра- зовательных целей через популяризацию и вербальную демонстрацию современных педагогических идей.

Данные утверждения подтверждаются реализующимися в научно-популярных педагогических текстах функциями. Приведем пример.

2. "Fourth grader Mario sits at his desk, staring at the page he is supposed to be reading. His eyes are not moving, and he has nothing in his hands to write with should he want to annotate or take notes. Noticing this, his teacher offers him a different text, an easier one. Mario starts to read the text. At least his eyes start moving across the page and he appears more engaged. There are two potential responses to this situation. Some would say that the teacher removed the challenge from Mario and should have instead scaffolded the reading. Others would say that the teacher did the right thing by ensuring that Mario had a text he could read. To our thinking, both are right depending on the task Mario was supposed to be doing" [Language magazine: Improving Literacy \& Communication, https://www.language magazine.com/].

Нельзя не заметить, что данный текстовый фрагмент также иллюстрирует процесс обучения чтению, два возможных подхода к решению педагогической задачи и профессиональную точку зрения в качестве ответа на вопрос о том, от чего может зависеть решение ситуации, возникшей в процессе обучения. Описывая потенциально возможную на занятии проблему, автор статьи передает читателю информацию, тем самым в НППД реализуется информативная функция. Кроме этого, данный пример несет воздействующий характер, направленный на восприятие читателем ситуации как действительно происходящей. Это подтверждается использованными автором языковыми средствами. Так, автор задает ситуацию с помощью предложения Mario sits at his desk, оживляет ситуацию глагольными формами staring at the page he is supposed to be reading, eyes are not moving, he has nothing, noticing this, teacher offers, Mario starts, his eyes start moving, противопоставляет профессиональные точки зрения в словосочетаниях some would say, should have instead $и$ others would say, teacher did the right thing. Формируя ощущение присутствия, автор заставляет читателя представить себя в подобной ситуации и проанализировать свои потенциальные действия. Очевидно, что, воздействуя таким образом на читателя, автор сообщения стремится к установлению открытого диалога со своей целевой аудиторией. Диалогичность высказываний и установление общности между участниками педагогического сообщества подтверждается выражением авторской точки зрения - to our thinking, both are right. Следует также заметить, что автор данной статьи руководствуется простым изложением педагогических идей. Следуя более свободному и доступному речевому поведению (в приведенном примере не наблюдается исполь- 
зования терминологической лексики или требующих отдельного пояснения профессионализмов), автор статьи увеличивает степень ее перцепции непрофессионалом [8, стр. 31], что в свою очередь приводит к популяризации специальных знаний об обучении чтению.

Итак, из вышесказанного становится очевидно, что НППД руководствуется частной необходимостью актуализировать и распространить профессиональные знания на большее количество реципиентов и упростить профессиональную систему понятий с диалоге между специалистами и неспециалистами. Тут заметим, что, реализуя цели НППД, его участники, а именно авторы проанализированных статей, стремятся к субъективизации дискурса, т.е. интеграции в языковое пространство читателя ценностных для педагогического сообщества концептов. Обратившись к предложенным примерам (1.), (2.), проанализировав их лексический состав с целью выявления тематической направленности и ключевых слов, сопоставив ключевые слова с их дефинициями в словарных статьях, мы выделили лексему READING как репрезентант одноименного ценностного концепта в нППД.

В британских словарях Cambridge Dictionary и Oxford Dictionary лексема reading имеет следующие дефиниции:

1. the skill or activity of getting information from books [Cambridge Dictionary, https://dictionary. cambridge.org/ dictionary/english/reading];

2. the particular way in which you understand a book, situation, etc. [Oxford Dictionary, https://www. oxfordlearnersdictionaries.com/definition/english/ reading_1?q=reading].

Данные дефиниции помогают нам в случае с первым текстовым фрагментом (1.), в котором отсутствует доминантная лексема reading, но присутствует обозначенная в первой дефиниции лексема information (background information, visual information, linguistic information). Концепт READING также актуализируется с помощью единицы storytellers, story, stories, settings, characters, входящих в его лексико-семантическое поле. Лексическая единица methods, название методик "elaborative assistance", "comprehension-aiding supplementation", оценка comprehensible раскрывают концепт READING как профессионально маркированный, т.е. являющийся частью концептосферы участников общения. Кроме этого, то, как моделируется и от чего отталкивается процесс обучения чтению (обозначенный в дефиниции 2. the particular way in which you understand / определенный способ, благодаря которому человек понимает написанное), читатель понимает с помощью единиц telling in advance, familiar settings or characters, pictures and drawings, synonyms, descriptions, transla- tion. Ознакомившись с данным текстовым фрагментом, читатель осознает значимость концепта READING для педагогического сообщества и признает многофакторность формирования читательских навыков у учащихся в процессе обучения.

Языковыми репрезентатами ценностного концепта READING в текстовом фрагменте (2.) являются непосредственно производные формы доминантной лексемы reading - to be reading, read и единицы, входящие в ее лексико-семантическую группу: page, text. Рассматривая концепт READING в качестве репрезентанта одного из аспектов обучения, отметим использование автором а) номинаций субъектов, включенных в процесс обучения: grader, teacher; б) номинаций действий субъектов обучающего процесса: write, annotate, take notes, offers, read, scaffolded; в) номинации, вербализирующей сам аспект обучения - reading; г) лексических единиц, репрезентирующих разного рода средства обучения: desk, text, task. Дискуссионность поднимаемого в статье вопроса, которая актуализируется в примере через местоимения some, others и our, с нашей точки зрения, говорит об озабоченности участников общения правильностью подбираемого алгоритма обучения, что, в свою очередь, может быть интерпретировано как выражение ценностных соображений.

Таким образом, данный анализ показывает, что научно-популярный педагогический дискурс представляет собой самостоятельное лингвопространство, которому присущи черты институциональной коммуникации. Как институт педагогическое сообщество транслирует профессиональную картину мира через участников общения, хронотоп, жанры, цель, функции и ценностные концепты. Актуализация данных компонентов и характер их функционирования в научно-популярных текстах не только популяризируют профессиональные знания, но и способствуют распространению и интериоризации аксиологических смыслов педагогического института: ознакомившись с текстами НППД, читатели приобретают ценностные установки и сознание, определяющие их способность давать оценку педагогическим реалиям и/ или совершенствовать свою профессиональную деятельность.

Увеличивающееся с каждым днем количество педагогического и образовательного контента в информационном пространстве социума, а также отсутствие комплексного лингвистического анализа научно-популярного педагогического дискурса обусловливают актуальность дальнейших исследований с целью использования полученных результатов не только в педагогических, но и междисциплинарных практиках. 


\section{ЛИТЕРАТУРА}

1. Бахтин М.М. Проблема речевых жанров // Бахтин М.М. Собрание сочинений в семи томах. - М.: Русские словари, 1996. - Т. 5. - С. $159-206$.

2. Егорова, Л.А. К вопросу об определении понятия «научно-популярный дискурс» // Вестник РУдН. Серия «Русский и иностранные языки и методика их преподавания». - 2009. - № 1. - С. 42-46.

3. Карасик В.И. Языковой круг: личность, концепты, дискурс. - Волгоград: Перемена, 2002. 477 с.

4. Караулов, Ю.Н. Русский язык. Энциклопедия. - М.: Большая Российская энциклопедия, 1997. 721 с.

5. Нерсесян Г.Р. Ценности англоязычного научно-популярного педагогического дискурса: лингвистические механизмы и лингвопрагматические закономерности // Научный диалог. - 2020. - № 9. - C. 111-127. - D0I: 10.24224/2227-1295-2020-9-111-127.

6. Попова 3.Д., Стернин И.А. Язык и национальное сознание // Изд.З., перераб. и доп. Воронеж: «Истоки» 2007.61 с.

7. Ромашова И.П. Модель институционального дискурса с позиций социодинамического подхода // Вестник Омского университета. - 2013. - № 1 (67). - С. 94-100.

8. Седов К.Ф. Дискурс и личность: эволюция коммуникативной компетенции. - М.: Лабиринт, 2004. 320 с.

9. Сластенин В.А., Чижакова Г.И. Введение в педагогическую аксиологию: Учеб. пособие для студ. высш. пед. учеб. заведений. - М.: Академия, 2003. 192 с.

10. Широкова Е.Н. Хронотоп текста, хронотоп дискурса (к вопросу разграничения текстовых и дискурсивных категорий) // Научное наследие Б.Н. Головина в свете актуальных проблем современного языкознания. - 2016. - С. 179-184.

11. Ширяева Т.А. Институциональность как важнейший дискурсообразующий фактор / Т.А. Ширяева // Человек. Язык. Культура: сборник научных статей, посвященный 60-летнему юбилею проф. В. И. Карасика. - Киев: Изд. дом Д. Бураго, 2013. - Ч. 1. - С. 780-790.

12. Шульман Е. [Беседа с редактором журнала Bookmate Journal B. Еременым] 11 сентября 2020 г. [Электронный ресурc]. - URL: https://journal.bookmate. com/ekaterina-shulman-ya-ne-veryu-chto-deti-travmiruyutsya-tekstami-tut-ya-raskhozhus-s-nyneshnej-moralyu/ (дата обращения: 30.09.2020).

13. Wierzbicka A.I. Introduction / A. Wierzbicka // Understanding Cultures through their Key Words: English, Russian, Polish, German, Japanese. - New York: Oxford University Press, 1997. $317 \mathrm{p}$.

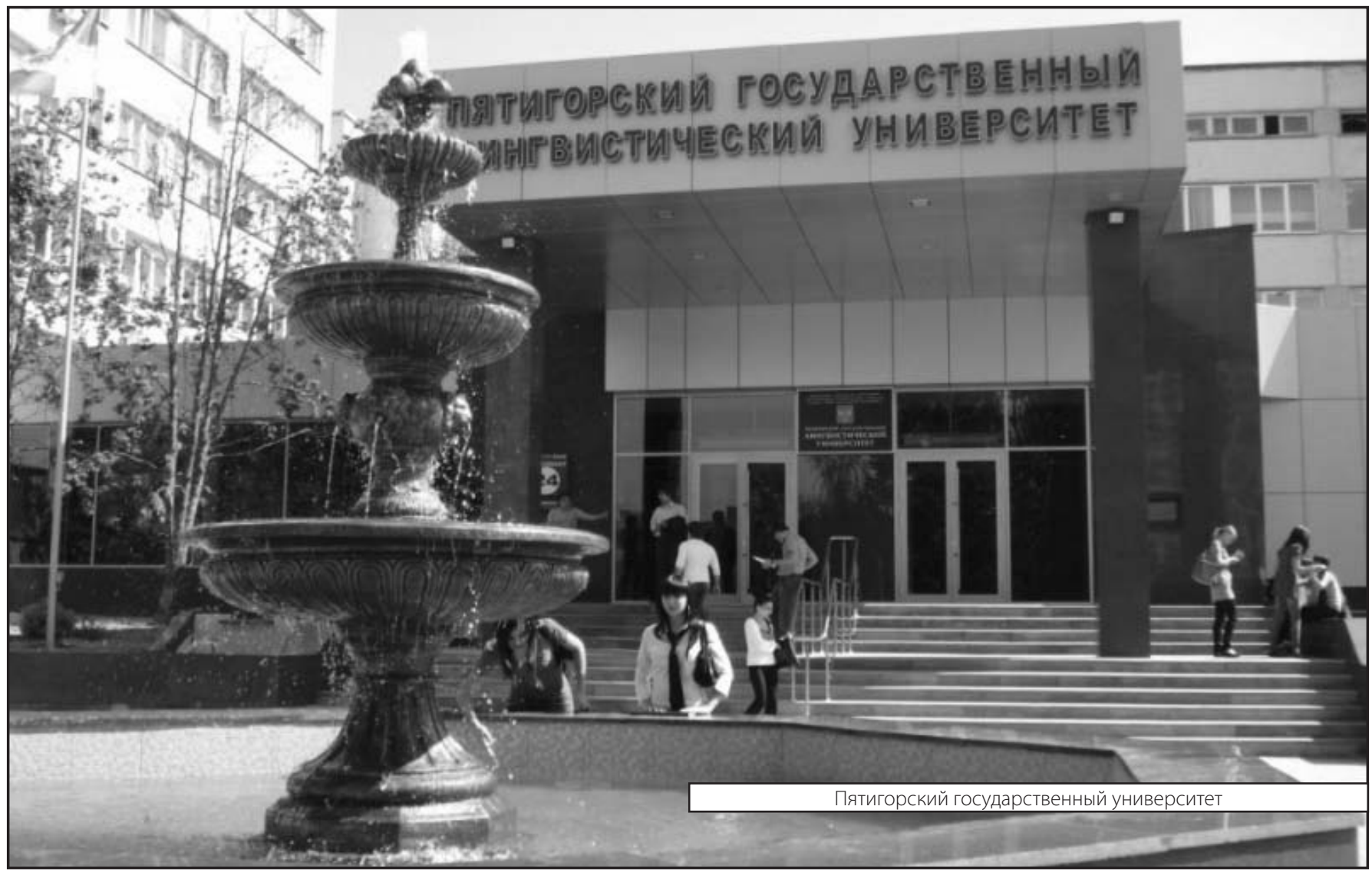

